\title{
Minor habituation to repeated experimental approaches in Scandinavian wolves
}

\author{
H. K. Wam • K. Eldegard • O. Hjeljord
}

Received: 9 June 2014 / Revised: 1 July 2014 / Accepted: 3 July 2014 / Published online: 13 July 2014

(C) Springer-Verlag Berlin Heidelberg 2014

\begin{abstract}
Large carnivores may become dangerous if they habituate to humans. We repeatedly approached wild wolves Canis lupus throughout a year to test their individual response to human encounters $(N=141$ trials $)$. None of the at least 25 wolves present during the study visually or vocally exposed themselves. The wolves fled at a mean distance of $248 \pm$ SE $11 \mathrm{~m}$ (range, 35-488 m). Their tolerance was most strongly influenced by the presence of site-dependent pups, while the distance at which they were initially alerted was most strongly influenced by detectability of human (wind and noise). The mean alert distance was $324 \pm 19 \mathrm{~m}$ in the first and $264 \pm 17 \mathrm{~m}$ in subsequent within-day trials, while tolerance distances showed no such trend, neither within a day nor throughout the year. The study indicates a high level of individual plasticity, making habituation difficult to predict.
\end{abstract}

Keywords Conservation · Disturbance · Flight initiation · Human conflict

Communicated by C. Gortázar

Electronic supplementary material The online version of this article (doi:10.1007/s10344-014-0841-0) contains supplementary material, which is available to authorized users.

H. K. Wam $(\bowtie)$

Organic Food and Farming Division, Norwegian Institute for Agricultural and Environmental Research, Gunnarsveg 6, 6630 Tingvoll, Norway

e-mail: hilde.wam@bioforsk.no

H. K. Wam $\cdot$ K. Eldegard $\cdot$ O. Hjeljord

Department of Ecology and Natural Resource Management, Norwegian University of Life Sciences, P.O. Box 5003, 1432 Ås, Norway

\section{Introduction}

Large carnivores may become dangerous if they habituate to humans (Løe and Röskaft 2004). Habituation can only be examined by monitoring the carnivore's response to human encounters over time. Even if no habituation is observed, monitoring may help to abate people's fear (but see Johansson and Karlsson 2011). A baseline reference point needs to be set specifically for the population of interest (Whittaker and Knight 1998). Previous experimental encounters between humans and large carnivores have been reported (e.g. Sunde et al. 1998; Sweanor et al. 2005; Karlsson et al. 2007; Moen et al. 2012). However, temporal habituation has not been investigated.

The main objective of this study was to experimentally assess the behavioural responses of individual wolves Canis lupus to repeatedly being approached by humans. We examined three potentially influential factors: (I) previous human encounters (within-day and throughout year repetition of experimental approaches),(II) wolf vulnerability (having site-dependent pups) and (III) detectability of human (i.e. environmental covariates such as wind and noise).

\section{Methods}

Study area and wolves

We used five wolf territories (300 to $950 \mathrm{~km}^{2}$ ) in mixed conifer-deciduous boreal forests in southern Scandinavia $\left(59^{\circ} 21^{\prime}-60^{\circ} 08^{\prime} \mathrm{N}\right)($ Table $\mathrm{S} 1)$. The forest cover ranged from 64-81\%, while open areas (not including cultivated land) constituted 12-18\% (Norwegian Mapping Authority 2005). Human impact ranged from 0.2 to $0.5 \mathrm{~km} / \mathrm{km}^{2}$ for roads, 2 to $22 / \mathrm{km}^{2}$ for residents and 1 to $37 \%$ for cultivated land. All territories had abundant wild prey. Six wolves were radio- 
collared, by darting them from helicopter (Sand et al. 2006). At the time of study, there had been no legal hunting since 1966 (Sweden) and 1972 (Norway), but the level of illegal hunting was substantial (Liberg et al. 2012).

Experimental approaches

We approached resting wolves during daytime, in two periods of different vulnerability of breeding wolves, i.e. with pups being (Jun-Aug) and not being (Sep-Mar) site-dependent. The trial design was balanced on period and environmental conditions (Table S2). The occurrence of killed prey near bed sites were negligible $(N=6)$. To test short-term effects of repeated encounters, a wolf was approached up to three times a day, if similar conditions could be obtained in repeated trials.

We located the wolves by ground-based VHF triangulation (transmitters with activity sensors). The same equipment was used throughout the study, and the same person was in charge of all triangulations. We had standardized procedures for obtaining fixes with adequate accuracy (Table S3). After a wolf was located, its activity was monitored by 'the observer' from a hill 600-800 m away and $\sim 90^{\circ}$ to 'the approacher' (the two communicating by radio). The approacher walked straight towards the wolf at a normal hiking speed $(\sim 1-2 \mathrm{~km} / \mathrm{h})$, either in silence or simulating a conversation. Deviations from normal surface noise were noted along the way (e.g. logging waste).

At the first sign of wolf activity (i.e. an increase in the transmission frequency), the approacher temporarily stopped and recorded the position with a handheld GPS (Garmin 12, Olathe, USA). If 'activity' lasted $>10 \mathrm{~s}$ without the wolf fleeing, the approach continued. When the wolf fled (i.e. a change in the signal direction), the approacher remained still until the animal resettled. With pre-coordinated watches, we simultaneously took VHF bearings of the fleeing wolf at set minute intervals.
Ethical note No trials were done during denning. When the wolves were at their early rendezvous sites in June, the approacher withdrew as soon as the wolves fled.

Data analyses

We analysed the data using generalized least square models ('gls' in the 'nlme' package in R 2.15.1, R Core Team). Wolf identity was included as a main term because we did not aim to generalize across species (safety issues with habituation are typically limited to nuisance individuals). Exploratory mixed models (wolf ID nested with pack ID as random) gave qualitatively similar results. We used four responses and five explanatory variables (Table S4). Additionally, we included the interactions 'wolf ID $\times$ trial\# and 'wolf ID $\times$ repeated trial' because habituation was of primary interest. There was considerable heterogeneity of variance in our data. We therefore fitted the models with the 'weights' option (Galecki and Burzykowksi 2013). After finding the optimal residual variance structure with restricted maximum likelihood estimation (REML), we did model selection by comparing nested models, using the 'drop1' approach, with the maximum likelihood estimation (MLE) technique and the likelihood ratio test (Zuur et al. 2009). After we had determined final models (all terms, $P \leq 0.05$ ), we refitted with REML and confirmed model adequacy by graphical validation.

\section{Results and discussion}

Overall outcome of experimental approaches

We successfully approached wolves 141 times (11 additional trials were not completed due to loss of signals). We logged

Table 1 Generalized least squares models explaining variation in behavioural responses of experimentally approached wild wolves in Scandinavia $(N$ total $=135$ trials, 5 individuals) ( $P$ values in parentheses)

\begin{tabular}{|c|c|c|c|c|}
\hline Fixed effect & Alert distance $^{\mathrm{a}}$ & Tolerance distance $^{\mathrm{a}}$ & Time to resettle ${ }^{\mathrm{b}}$ & Fleeing distance ${ }^{c}$ \\
\hline Wolf identity (ID) & $F_{4,126}=3(0.0367)$ & $F_{4,128}=14(<0.0001)$ & $F_{4,105}=13(<0.0001)$ & $F_{4,100}=4(0.0024)$ \\
\hline \multicolumn{5}{|l|}{ Trial\# } \\
\hline Within-day trial & $F_{1,126}=7(0.0120)$ & & $F_{1,105}=42(<0.0001)$ & $F_{1,100}=9(0.0037)^{\mathrm{e}}$ \\
\hline Wolf vulnerability & $F_{1,126}=157(<0.0001)$ & $F_{1,128}=265(<0.0001)$ & & \\
\hline Detectability & $F_{1,126}=1403(<0.0001)$ & $F_{4,128}=146(<0.0001)$ & & \\
\hline $\mathrm{ID} \times$ trial $\#$ & & & & $F_{4,100}=6(0.0005)$ \\
\hline ID $\times$ within-day trial & & & $F_{4,105}=8(0.0620)$ & $F_{4,100}=3(0.0410)$ \\
\hline ID $\times$ vulnerability $^{\mathrm{d}}$ & $F_{2,99}=3(0.0710)$ & $F_{2,101}=18(<0.0001)$ & & \\
\hline
\end{tabular}

${ }^{a}$ varIdent variance structure due to heterogeneity in variances within the wolf ID stratum

${ }^{\mathrm{b}}$ varComb variance structure (heterogeneity in a range of trial\#, and in the vulnerability, repeated trial and wolf ID strata)

${ }^{\mathrm{c}}$ varIdent variance structure (heterogeneity in vulnerability, repeated trial and wolf ID strata)

${ }^{\mathrm{d}}$ In post hoc model with adult wolves only (detectability $F=149, P<0.0001$; vulnerability $F=109, P<0.0001$; wolfID $F=5, P<0.0001$ )

${ }^{\mathrm{e}}$ Largely due to a few extreme observations 
1,512 man-hours $<1 \mathrm{~km}$ from wolves, plus 904 man-hours at unknown distances from the at least 25 wolves present (Table S1). No wolf exposed itself, neither visually nor vocally. The wolves moved off, more or less straight ahead, as they did in Karlsson et al. (2007). The studies show that in Scandinavia the chance for a wolf to confront a moving hiker is diminishingly small .

On average, alert distances were $293 \pm$ SE $13 \mathrm{~m}$ and tolerance distances were $248 \pm 11 \mathrm{~m}$ (Table S3). The wolves moved sparingly when fleeing: spending a median of $8 \mathrm{~min}$ (first-third quartile, 6-15) and moving a median of $351(201-573) \mathrm{m}$ to resettle. They also resettled on more concealed sites (Wam et al. 2012). The tolerance of Scandinavian wolves is low compared to other large carnivores in comparable settings (mean distances, 20-70 m; see Introduction). Apparently, other carnivores are more inclined to hiding. While each species may have an evolutionary conditioned preference, there is also individual plasticity, as indicated by the broad influence of 'wolfID' in our study (Table 1).

Influence of detectability

Tolerance distances were 200-250 $\mathrm{m}$ shorter for the lowest detectability (person in a headwind on soft surfaces with no conversation) compared to the highest detectability (Fig. 1). Similarly, the alert distance was $200-400 \mathrm{~m}$ shorter, and here, the influence of detectability superseded other factors. The influence of detectability is expected. Wolves can pick up scent (Moulton and Marshall 1976) or sound

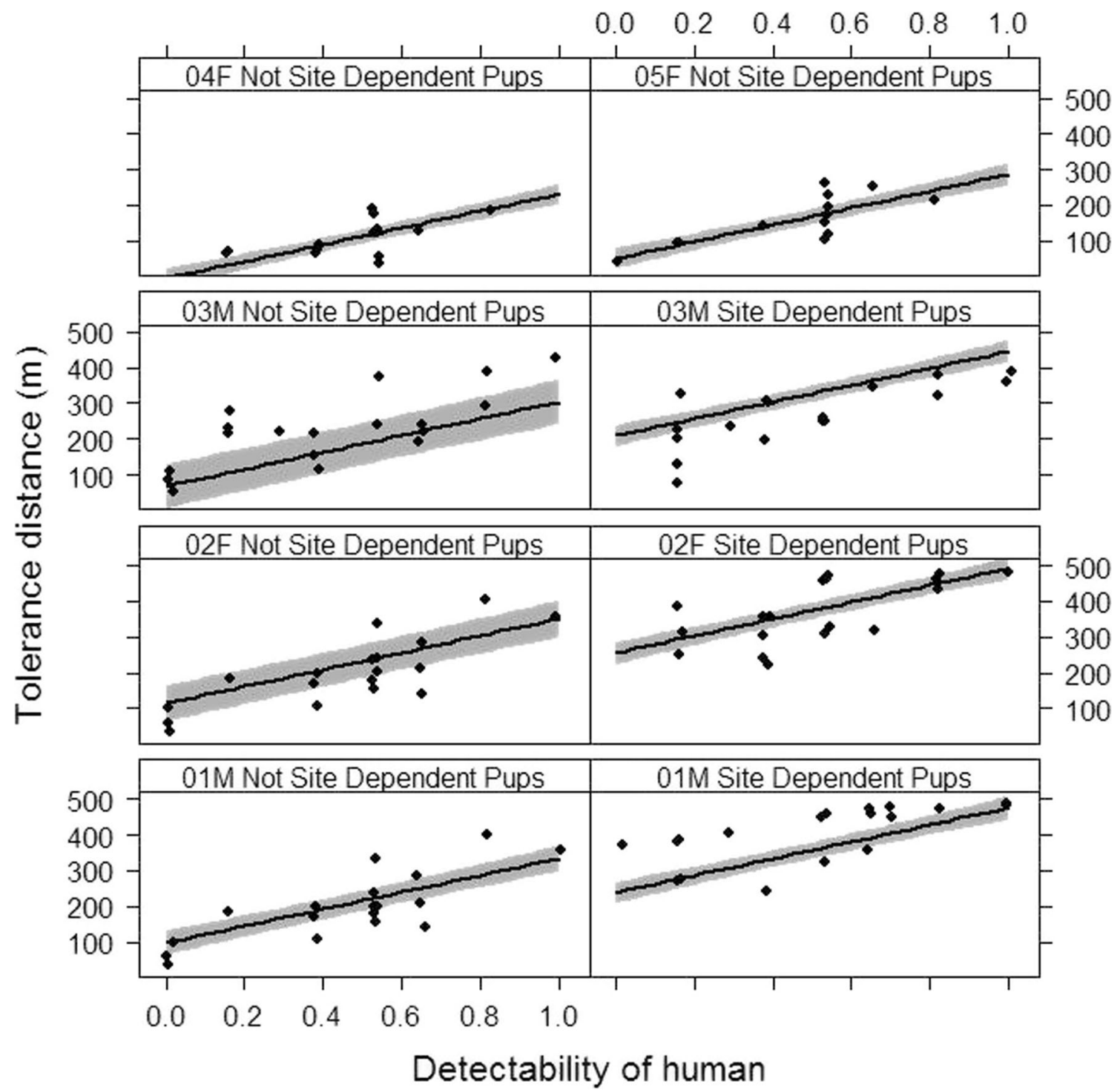

Fig. 1 Individual tolerance of experimentally approached wild wolves in Scandinavia ( $N=135$ trials). Breeding wolves were approached in two periods of different vulnerability (with or without site-dependent pups). Wolf 04F and
05F were approached in latter period only. Detectability of human was indexed by wind and noise (higher values for person approaching in tailwind and with more noise). Dots are observed values; shaded area is $95 \% \mathrm{CI}$ 
(Harrington and Mech 1979) at several hundred metres, even in rugged terrain.

Influence of vulnerability

Vulnerability was a stronger factor than detectability in explaining tolerance, indicating that wolves do not flee instinctively. The breeding wolves tolerated the approacher to come about 1.5 times closer when they did not have sitedependent pups (Fig. 1). Both in cougars (Sweanor et al. 2005) and in bears (Swenson et al. 1999) the presence of cubs are overrepresented in the statistics of attacks on humans. The strategy of fleeing from site-dependent pups may make the wolves more exposed to illegal killing pups at the den. The wolves also showed an almost twice as long alert distance with site-dependent pups compared to without (Fig. S1).

\section{Influence of previous approaches}

Previous approaches had no significant influence on tolerance distances (Fig. S2), although there was a slight trend of lower tolerance in repeated trials for breeding wolves with sitedependent pups (Fig. S3). Alert distances went down from $324 \pm 19 \mathrm{~m}$ in first to $264 \pm 17 \mathrm{~m}$ in repeated trials, while time to resettle increased (Fig. S4). Habituation in large carnivores is a debated topic due to lack of generalizing patterns (Treves and Karanth 2003), ambiguous definitions and few true experiments (Smith et al. 2005). It seems that habituation in wolves occurs mainly when people actively seek to tame the animals (McNay 2002). It took only one intensive summer to habituate an arctic pack to tolerate human presence (Mech 1988), while wolves on Isle Royale have remained fearful of man after five decades with no hunting and thousands of visitors (Peterson and Vucetich 2002). The fact that our knowledge about habituation in wolves is so limited suggests that it should be proactively monitored.

Acknowledgments We thank C Rossebø Isdahl, A Alfredsson, JG Dokk and OK Sauge for contributing extensively during the timeconsuming field work.

\section{References}

Galecki A, Burzykowksi T (2013) Linear mixed-effects models using R. Springer, New York

Harrington FH, Mech LD (1979) Wolf howling and its role in territory maintenance. Behaviour 68:207-249

Johansson M, Karlsson J (2011) Subjective experience of fear and the cognitive interpretation of large carnivores. Hum Dimens Wildl 16: $15-29$

Karlsson J, Eriksson M, Liberg O (2007) At what distance do wolves move away from an approaching human? Can J Zool 85:1193-1197

Liberg O, Chapron G, Wabakken P, Pedersen HC, Hobbs NT, Sand H (2012) Shoot, shovel and shut up, cryptic poaching slows restoration of a large carnivore in Europe. Proc R Soc B 279:910-915

Løe J, Röskaft E (2004) Large carnivores and human safety, a review. AMBIO 33:283-288

McNay ME (2002) Wolf-human interactions in Alaska and Canada: a review of the case history. Wildl Soc Bull 30:831-843

Mech LD (1988) The arctic wolf, living with the pack. Voyageur Press, Minnesota

Moen GK, Støen OG, Sahlén V, Swenson JE (2012) Behaviour of solitary adult Scandinavian brown bears when approached by humans on foot. PLoS One 7:e31699

Moulton DG, Marshall DA (1976) The performance of dogs in detecting alpha-ionone in the vapour phase. J Comp Physiol 110:287-306

Norwegian Mapping Authority (2005) Land statistics Norway, Oslo

Peterson RO, Vucetich JA (2002) Ecological studies of wolves on Isle Royale. Ann Report 2001- 2002, Michigan Technological University

Sand H, Wikenros C, Wabakken P, Liberg O (2006) Effects of hunting group size, snow depth and age on the success of wolves hunting moose. Anim Behav 72:781-789

Smith TS, Herrero S, DeBruyn TD (2005) Alaskan brown bears, humans, and habituation. Ursus 16:1-10

Sunde P, Stener SØ, Kvam T (1998) Tolerance to humans of resting lynxes Lynx lynx in a hunted population. Wildl Biol 4:177-183

Sweanor LL, Logan KA, Hornocker MG (2005) Puma responses to close approaches by researchers. Wildl Soc Bull 33:905-913

Swenson JE, Sandegren F, Söderberg A, Heim M, Sørensen OJ, Bjärvall A, Franzén R, Wikan S, Wabakken P (1999) Interactions between brown bears and humans in Scandinavia. Biosph Cons 2:1-9

Treves A, Karanth KU (2003) Human-carnivore conflict and perspectives on carnivore management worldwide. Cons Biol 17: 1491-1499

Wam HK, Eldegard K, Hjeljord O (2012) From overlooking to concealed, predator avoidance in an apex carnivore. Eur J Wildl Res 58: 1001-1003

Whittaker D, Knight RL (1998) Understanding wildlife responses to humans. Wildl Soc Bull 26:312-317

Zuur AF, Ieno EN, Walker NJ, Saveliev AA, Smith GM (2009) Mixed effects models and extensions in ecology with R. Springer, New York 